\title{
DAYA DUKUNG PERAIRAN WADUK JATILUHUR UNTUK BUDI DAYA IKAN DALAM KERAMBA JARING APUNG
}

\author{
Adriani Sri Nastiti"), Siti Nuroniah"), Sri Endah Purnamaningtyas*), dan Endi Setiadi Kartamihardja*'
}

\begin{abstract}
ABSTRAK
Kegiatan budi daya ikan di Waduk Jatiluhur yang berkembang pesat saat ini, telah menurunkan kualitas perairannya. Oleh karena itu data dan informasi tentang daya dukung perairan sangat diperlukan dalam rangka pengelolaan budi daya ikan di perairan Waduk Jatiluhur. Tujuan penelitian ini untuk mendapatkan data dan informasi daya dukung perairan Waduk Jatiluhur menurut musim pada budi daya ikan dalam keramba jaring apung (KJA). Penelitian ini dilakukan di Waduk Jatiluhur pada bulan Mei sampai Desember 1998. Metode pengambilan contoh air adalah strata, baik daerah penelitian maupun kedalaman perairan. Daerah penelitian meliputi: Dam, KJA, Pagadungan, dan Warungjeruk. Kedalaman perairan meliputi : $0 \mathrm{~m}, 1 \mathrm{~m}, 2 \mathrm{~m}, 3 \mathrm{~m}, 4 \mathrm{~m}, 5 \mathrm{~m}, 10$ $m$, dan dasar perairan. Dalam penelitian ini oksigen terlarut dan luas serta volume air Waduk Jatiluhur merupakan parameter yang digunakan untuk penghitungan daya dukung perairan. Sedangkan parameter lainnya yang diukur adalah kelimpahan fitoplankton dan klorofil-a. Hasil penelitian menunjukkan bahwa daya dukung Waduk Jatiluhur untuk budi daya ikan dalam KJA tertinggi pada bulan Juli (musim kemarau) dan terendah pada bulan Desember (musim hujan). Pada bulan Juli total oksigen terlarut untuk ikan adalah $240 \times 10^{10} \mathrm{mg}$ atau $480 \times 10^{3} \mathrm{~kg}$ ikan, dengan bobot ikan $10 \mathrm{~g} / \mathrm{ekor}$ dengan jumlah KJA 653 unit (ukuran $98 \mathrm{~m}^{3} / \mathrm{unit}$ ). Pada bulan Desember (musim hujan) total oksigen terlarut untuk ikan adalah $160 \times 10^{10} \mathrm{mg}$ atau $130 \times 10^{3} \mathrm{~kg}$ ikan, dengan jumlah KJA 177 unit (ukuran 98 m³/unit). Disarankan kepada petani KJA agar pada bulan Desember (musim hujan) memilih alternatif mengatasi kematian ikan dengan mengurangi padat tebar ikan, menghindari pemeliharaan ikan pada bulan Desember, mengganti jenis ikan yang toleran terhadap kandungan $\mathrm{O}_{2}$ yang rendah seperti ikan pangasius.
\end{abstract}

ABSTRACT: Carrying capacity of Jatiluhur reservoir for fish net cage culture. By: Adriani Sri Nastiti, Siti Nuroniah, Sri Endah Purnamaningtyas, and Endi Setiadi Kartamihardja

At present, impact of the blooming fish culture actives Jatiluhur reservoir is decreasing its water quality. Therefore, data and information on carrying capacity are needed for fish culture management in the reservoir. The aim of this research was to obtain data and information on the carrying capacity of Jatiluhur reservoir by season for fish net cage culture. The research was conducted on May - December 1998 at ten stations i.e., : Dam (2), KJA (4), Pagadungan (2), and Warungjeruk (2) by depth: $0 \mathrm{~m}$ (surface), $1 \mathrm{~m}, 2 \mathrm{~m}, 3 \mathrm{~m}, 4 \mathrm{~m}, 5 \mathrm{~m}, 10 \mathrm{~m}$, and at bottom using stratified sampling method. Parameter measured were: dissolved oxygen, abundance of phytoplankton, chlorophyl-a as well as area and volume of Jatiluhur reservoir. The result showed that the carrying capacity Jatiluhur reservoir for fish net cage culture on July (dry season) was the highest where total oxygen dissolved for fish was about $240 \times 10^{10} \mathrm{mg}$ or $480 \times 10^{3} \mathrm{~kg}$ fish of $10 \mathrm{~g}$ each. The total number of floating net cage operating was about 653 units ( $98 \mathrm{~m}^{3} / \mathrm{unit}$ ). On December (rainy season) the carrying capacity was at the lowest, where total dissolved oxygen was $160 \times 10^{10} \mathrm{mg}$ or $130 \times 10^{3} \mathrm{~kg}$ fish weight of $10 \mathrm{~g}$ each. The total number of floating net cages operating was 177 units (98 $\mathrm{m}^{3} / \mathrm{unit}$ ). Recomendations given to fish farmers on December (rainy season) to decrease mortality are : to decrease fish density, to harvest fish, and to use fish which has high tolerance to low $\mathrm{O}_{2}$ i.e., pangasius.

KEYWORDS : carrying capacity, fish net cage culture, oxygen dissolved, Jatiluhur reservoir

\section{PENDAHULUAN}

Keberhasilan pengembangan budi daya ikan dalam keramba jaring apung (KJA) berdampak positif terhadap peningkatan produksi ikan di keramba dari tahun 1968 sampai dengan 1993. Produksi keramba diproyeksikan sebesar $142,92 \%$ per tahun sedangkan teknologi budi daya yang lain tidak lebih dari $10 \%$ per tahun (Ilyas \& Supardan, 1990). Luas perairan danau dan waduk yang potensial untuk usaha budi daya ikan dengan KJA adalah 18.000 ha (Hardjamulia, et al., 1992 dalam Ismail \& Wardoyo, 1997).

\footnotetext{
Peneliti pada Pusat Riset Perikanan Tangkap

") Peneliti pada Pusat Riset Perikanan Budidaya
} 
Perkembangan unit KJA yang pesat telah berdampak positif terhadap peningkatan produksi ikan dan pendapatan petani ikan. Di pihak lain, peningkatan jumlah unit KJA yang kurang terkendali telah menimbulkan masalah yang berdampak negatif terhadap lingkungan perairan. Dampak negatif yang ditimbulkan antara lain disebabkan kurang diperhatikannya prinsip-prinsip teknologi dalam budi daya ikan dengan sistem $\mathrm{KJ} A$ seperti cara pemberian pakan dengan sistem pompa, kurang memperhatikan daya dukung perairan, dan tata letak KJA (Kartamihardja, 1995). Akibat langsung dari penurunan kualitas air adalah terjadinya kematian ikan.

Berkembangnya budi daya ikan dalam keramba jaring apung (KJA) perlu memperhatikan daya dukung perairan. Daya dukung perairan didefinisikan sebagai tingkat produksi ikan maksimal yang dapat dihasilkan dari perairan tersebut secara berkelanjutan (Beveridge, 1987). Daya dukung perairan selalu berfluktuasi menurut musim dan dapat menurun karena cemaran, misalnya tingginya sisa pakan dan kotoran ikan yang masuk ke perairan. Di Waduk Jatiluhur kegiatan budi daya ikan dalam KJA telah berjalan tanpa memperhatikan teknologi yang sudah ada. Pemberian pakan dengan sistem pompa akan menyebabkan penumpukan pakan yang tidak termakan di dasar perairan.

Salah satu masalah yang ditimbulkan dari praktek budi daya ikan dalam KJA intensif adalah pencemaran lingkungan perairan dari pakan yang terbuang dan sisa atau kotoran ikan yang akan merangsang produktivitas perairan dan mempengaruhi karakteristik biotik dan abiotik perairan. Pada kondisi yang tidak berlebihan, unsur hara (terutama $\mathrm{N}$ dan $\mathrm{P}$ ) yang dihasilkan dari kegiatan budi daya akan merangsang pertumbuhan fitoplankton (algae) dan meningkatkan produktivitas perairan. Sebaliknya, dalam keadaan yang berlebihan akan menurunkan kualitas perairan dan dalam keadaan ekstrim akan menyebabkan kematian ikan budi daya serta memacu timbulnya penyakit ikan (Beveridge, 1987). Berdasarkan pengukuran kandungan $\mathrm{O}_{2}$ terlarut di Waduk Jatiluhur pada bulan November sampai dengan Januari menghasilkan kandungan $\mathrm{O}_{2}$ terlarut rendah. Akibat dari hal tersebut pada awal bulan Januari tahun 1996 di Waduk Jatiluhur terjadi kematian ikan budi daya sebesar 1.560 ton (Krismono et al., 1997). Kematian massal ikan budi daya dalam KJA tersebut dapat ditanggulangi dengan menyeimbangkan antara daya dukung perairan dengan faktor-faktor internalnya (jenis, kepadatan, ukuran ikan, jumlah dan kualitas pakan) sebagai input atau dengan kata lain menyeimbangkan antara kelarutan $\mathrm{O}_{2}$ yang dibutuhkan ikan dengan kelarutan $\mathrm{O}_{2}$ di perairan (Kartamihardja, 1995).
Daya dukung perairan berfluktuasi menurut musim, maka daya dukung perairan Waduk Jatiluhur merupakan informasi penting untuk mengetahui gambaran fluktuasinya, terutama pada saat kondisi kritis.

\section{BAHAN DAN METODE}

Penelitian dilakukan di Waduk Jatiluhur baik di lokasi budi daya KJA maupun di luar lokasi KJA. Daya dukung perairan dihitung berdasarkan pola distribusi kandungan $\mathrm{O}_{2}$ terlarut musiman (Hartoto, 1998). Parameter lainnya yang dibutuhkan dalam menentukan daya dukung perairan adalah luas dan volume air waduk. Sebagai data dukung dilakukan pula pengukuran kelimpahan fitoplankton dan klorofil-a. Oksigen terlarut diukur dengan DO-meter secara insitu. Jenis dan kelimpahan fitoplankton diidentifikasi dan dihitung di laboratorium dengan bantuan mikroskop. Klorofil-a dianalisis di laboratorium dengan bantuan alat spectrofotometer, sedangkan data tentang luas dan volume Waduk Jatiluhur diperoleh dari Perum Jasa Tirta II (PJT II).

Pengambilan sampel air untuk menentukan kandungan $\mathrm{O}_{2}$ terlarut, kelimpahan fitoplankton, dan klorofil-a dilakukan dengan metode strata (Nielsen \& Johnson, 1985) di 10 stasiun yaitu : KJA I, KJA II, KJA III, KJA IV, Dam I, Dam II, Pagadungan I, Pagadungan II, Warungjeruk I, Warungjeruk II (Gambar 1). Kandungan $\mathrm{O}_{2}$ terlarut diukur pada permukaan perairan dan kedalaman air: $1 \mathrm{~m}, 2 \mathrm{~m}, 3 \mathrm{~m}, 4 \mathrm{~m}, 5 \mathrm{~m}$, $10 \mathrm{~m}$ dan dasar perairan, sedangkan untuk kelimpahan fitoplankton dan klorofil-a diamati pada permukaan perairan dan kedalaman air: $1 \mathrm{~m}, 2 \mathrm{~m}, 3 \mathrm{~m}, 4 \mathrm{~m}, 5 \mathrm{~m}$ dan $10 \mathrm{~m}$. Pengukuran parameter ini disesuaikan dengan kedalaman eufotik Waduk Jatiluhur sampai kedalaman 10-11m (Nastiti, 1989).

Pada tahap pendahuluan telah dilakukan pula pengukuran $\mathrm{O}_{2}$ terlarut selama 24 jam dengan selang waktu 2 jam di daerah KJA sebanyak 2 kali pengukuran yaitu 1 kali musim hujan dan 1 kali musim kemarau.

Dalam perhitungan daya dukung diasumsikan bahwa jumlah $\mathrm{O}_{2}$ terlarut yang digunakan ikan untuk respirasi yaitu sekitar $10 \%$, dan konsumsi oksigen oleh benih ikan berukuran 10 gram sebanyak $5 \mathrm{mg}$ $\mathrm{O}_{2}$ /jam (Hartoto, 1997).

Daya dukung Waduk Jatiluhur untuk budi daya ikan dengan KJA dihitung berdasarkan data sebagai berikut:

\section{Luas Waduk Jatiluhur}

2. Volume air Waduk Jatiluhur

3. Kolom air yang baik untuk kehidupan ikan (berdasarkan kandungan $\mathrm{O}_{2}$ terlarut) 

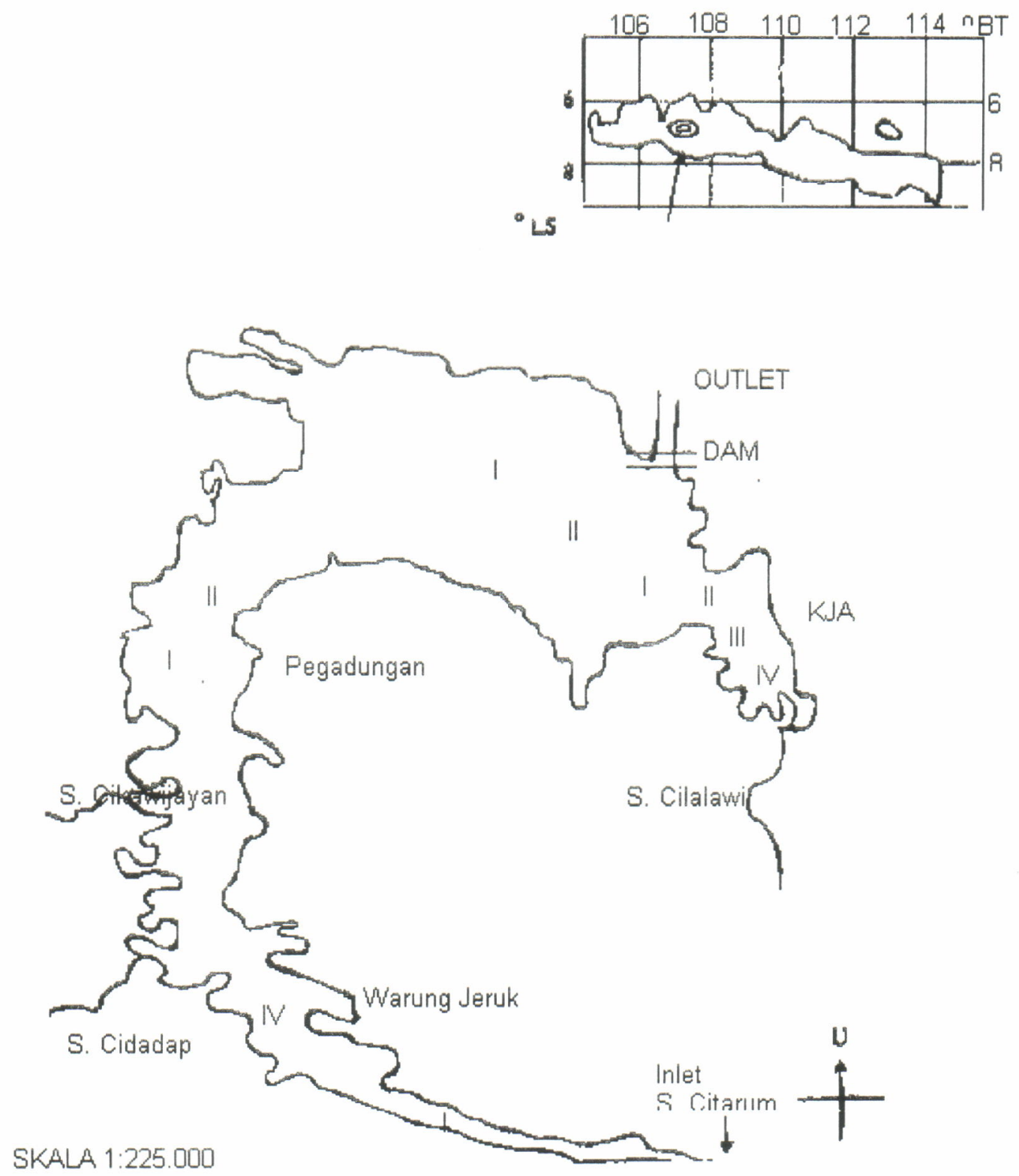

Gambar 1. Lokasi penelitian di Waduk Jatiluhur, Jawa Barat

Figure 1. Sampling station in Jatiluhur Reservoir, West Java 
4. Volume air Waduk Jatiluhur yang sesuai untuk kehidupan ikan $(\mathrm{V})$

5. Kebutuhan $\mathrm{O}_{2}$ terlarut oleh benih ikan (A)

6. Daya dukung: $\mathrm{V} \times \mathrm{A}=\mathrm{VA}$

7. Jumlah ikan yang ditebar: $V A / A=V k g$

8. Dengan asumsi padat tebar benih ikan pada KJA ukuran $98 \mathrm{~m}^{3}$ : 100-150 kg maka jumlah KJA di Waduk Jatiluhur antara V/100 sampai V/150 unit KJA Waduk Jatiluhur V/ 735 unit KJA.

\section{HASIL DAN BAHASAN}

Hasil penelitian menunjukkan bahwa daya dukung perairan Waduk Jatiluhur yang paling rendah terjadi pada bulan Desember sesuai dengan rendahnya kandungan $\mathrm{O}_{2}$ terlarut (Tabel 1 ). Rendahnya kandungan $\mathrm{O}_{2}$ pada bulan Desember diduga karena beberapa faktor di antaranya adalah pada bulan Desember curah hujan tinggi sehingga bahan organik yang berupa sampah dan pakan yang terbuang dari kegiatan budi daya ikan dalam KJA di Waduk Cirata dari \pm 30.000 unit KJA melalui Sungai Citarum masuk ke Waduk Jatiluhur, demikian pula bahan organik dari kegiatan pertanian dan pemukiman di sekitar Waduk Jatiluhur akan masuk ke perairan bersama dengan air hujan. Volume air waduk paling rendah terjadi pada bulan Desember (musim hujan) yaitu $13.688 \times 10^{5} \mathrm{~m}^{3}$ tidak mampu menetralisir sampah yang begitu besar. Kandungan $\mathrm{O}_{2}$ terlarut yang tersedia di perairan dipakai untuk proses dekomposisi bahan organik.

Pada musim hujan bulan Oktober sampai Desember dan Mei kelimpahan fitoplankton yang dominan sebagai pakan alami di perairan Waduk Jatiluhur adalah Navicula, Staurastrum, Synedra, dan Diatomae dengan kepadatan berkisar antara 4.828$8.024 \mathrm{sel} / \mathrm{L}$ (Tabel 2), sedang pada musim kemarau bulan Juni sampai September fitoplankton yang dominan adalah Phormidium, Chlorella, Peridinium, dan Synedra dengan kepadatan berkisar antara 4.080$4.760 \mathrm{sel} / \mathrm{L}$.

Berdasarkan Tabel 2 dan Tabel 3, pada musim hujan fitoplankton yang memiliki klorofil-a (Cyanophyta dan Chlorophyta) hanya 34.086 sel, sedangkan fitoplankton yang memiliki klorofil-c (Chrysophyta dan Pyrrophyta) sejumlah 58.590 sel. Pada musim kemarau fitoplankton yang memiliki klorofil -a (Cyanophyta dan Chlorophyta) lebih besar dibandingkan pada musim hujan yaitu 38.896 sel, sedangkan fitoplankton yang memiliki klorofil-c (Chrysophyta dan Pyrrophyta) sejumlah 49.242 sel. Walaupun terjadi keadaan yang khusus pada bulan September (musim kemarau), nilai rata-rata klorofil-a rendah $(12,05 \pm 2,598)$ dibandingkan dengan nilai ratarata klorofil-a pada bulan-bulan lainnya (Tabel 4). Bila nilai tersebut dibandingkan dengan kriteria kesuburan perairan menurut Ryding \& Rast (1989) maka perairan Waduk Jatiluhur termasuk dalam klasifikasi perairan yang eutrofik. Rendahnya klorofil-a pada musim hujan diduga berhubungan dengan kelimpahan fitoplankton yang memiliki jenis klorofil lainnya. Menurut Gupta (1981) genus fitoplankton yang memiliki klorofil-a adalah sebagian besar dari phyllum Chlorophyta, Cyanophyta, Rhodophyta, Phaeophyta, dan Bacillariophyta. Fitoplankton yang memiliki klorofil-b adalah sebagian dari phyllum Chlorophyta dan sebagian besar Euglenophyta. Klorofil-c terdapat pada Chrysophyta, Pyrrophyta, Chrysophyta, dan sebagian pada Phaeophyta dan Baccillariophyta. Klorofil-d hanya dimiliki oleh Rhodophyta. Klorofil-e pada genera Tribonema phyllum Xanthophyta dan Vaucheria dari Zoospore.

Daya dukung (total kandungan $\mathrm{O}_{2}$ terlarut) pada bulan Desember rendah yaitu $160 \times 10^{10} \mathrm{mg}$ atau dengan bobot benih ikan $130 \times 10^{3} \mathrm{~kg}$ atau dengan jumlah KJA 176,87 unit dengan asumsi bobot ikan per ekor $10 \mathrm{~g}$ dan ukuran keramba $7 \times 7 \times 2 \mathrm{~m}^{3}$. Berdasarkan daya dukung tersebut maka petani ikan KJA harus selalu waspada pada saat musim hujan khususnya pada bulan Desember karena daya dukung perairan rendah. Pada bulan tersebut petani KJA disarankan untuk mengurangi padat tebar ikan dan memanen ikan serta mengganti jenis ikan yang toleran terhadap kandungan $\mathrm{O}_{2}$ yang rendah seperti pangasius (Pangasiodon hypopthalmus)

Pada musim kemarau (Juni sampai dengan September) daya dukung perairan tinggi terutama pada bulan Juli, dengan total oksigen terlarut yang dapat dimanfaatkan ikan $240 \times 10^{10} \mathrm{mg}$ atau dengan bobot benih $480 \times 10^{3} \mathrm{~kg}$ ikan atau jumlah KJA 3.200-4.800 unit. Peningkatan daya dukung pada musim kemarau berhubungan dengan peningkatan volume air yang mencapai $38.190 \times 10^{5} \mathrm{~m}^{3}$ dan kandungan oksigen terlarut yang cukup tinggi yaitu $6,3 \mathrm{mg} / \mathrm{L}$, sedangkan pada bulan Agustus volume air maksimal ( $38.260 \mathrm{x}$ $\left.10^{5} \mathrm{~m}^{3}\right)$ dengan kandungan oksigen lebih rendah $(5,2$ $\mathrm{mg} / \mathrm{L}$ ) sehingga daya dukung perairan pun lebih rendah dibandingkan pada bulan Juli.

Bila dibandingkan dengan jumlah unit KJA di Waduk Jatiluhur yang sekarang ini sekitar 2.500 unit maka dapat diketahui bahwa jumlah unit KJA masih di bawah ketentuan minimal hasil perhitungan, tetapi perlu waspada bahwa jumlah unit tersebut hanya berlaku pada saat kandungan $\mathrm{O}_{2}$ terlarut tinggi saja. Dari hasil perhitungan pada Tabel 1 penambahan jumlah unit KJA dapat dilakukan untuk lebih meningkatkan produksi perairan namun perlu didistribusikan di lokasi lainnya di Waduk Jatiluhur 
Nastiti A.S., S. Nuroniah, S.E. Purnamaningtyas, dan E.S. Kartamihardja

Tabel 1. Daya dukung Waduk Jatiluhur untuk budi daya ikan dalam keramba jaring apung

Tabel 1. Carrying capacity in Jatiluhur Reservoir for fish culture in floating net cage

\begin{tabular}{|c|c|c|c|c|c|c|c|c|}
\hline \multirow{2}{*}{ Parameter } & \multicolumn{8}{|c|}{ Bulan (Month) 1998} \\
\hline & Mei & Juni & Juli & Ags & Sept & Okt & Nop & Des \\
\hline $\begin{array}{l}\text { Luas total waduk }\left(\times 105 \mathrm{~m}^{2}\right) \\
\text { Area }\left(\times 105 \mathrm{~m}^{2}\right)\end{array}$ & 6,837 & 7,297 & 7,638 & 7,652 & 7,168 & 6,691 & 6,956 & 6,844 \\
\hline $\begin{array}{l}\text { Kedalaman KJA yang aman }(m) \\
\text { Safe depth of fish net cage }(m)\end{array}$ & 4 & 5 & 5 & 5 & 5 & 5 & 5 & 2 \\
\hline $\begin{array}{l}\text { Volume waduk }\left(\times 105 \mathrm{~m}^{3}\right) \\
\text { Volume of reservoir }\left(\times 105 \mathrm{~m}^{3}\right)\end{array}$ & 27,348 & 36,395 & 38,190 & 38,260 & 35,840 & 34,780 & 34,780 & 13,688 \\
\hline $\begin{array}{l}\text { Rata-rata } \mathrm{O}_{2} \text { terlarut }(\mathrm{mg} / \mathrm{L}) \\
\text { Average of dissolved } \mathrm{O}_{2}(\mathrm{mg} / \mathrm{L}) \\
\text { Daya dukung : } \\
\text { Carming capacity: }\end{array}$ & 5.4 & 6.4 & 6.3 & 5.2 & 6.08 & 4.63 & 6.3 & 4.6 \\
\hline $\begin{array}{l}\text { Total } \mathrm{O}_{2} \text { terlarut }(\times 1010 \mathrm{mg}) \\
\text { Total of } \mathrm{O}_{2} \text { dissolved }(\times 1010 \mathrm{mg})\end{array}$ & 1,500 & 2,300 & 2,400 & 2,000 & 2,200 & 1,500 & 2,200 & 1,600 \\
\hline $\begin{array}{l}\text { Total } \mathrm{O}_{2} \text { untuk ikan }(\times 1010 \mathrm{mg})^{*} \\
\text { Oxygen for fish }(\times 1010 \mathrm{mg})^{*}\end{array}$ & 150 & 230 & 240 & 200 & 220 & 150 & 220 & 160 \\
\hline $\begin{array}{l}\text { Bobot benih }(\times 103 \mathrm{~kg} \mathrm{ikan})^{\star * *} \\
\text { Weight of fish seed }(\times 103 \mathrm{~kg} \text { fish })^{\star *}\end{array}$ & 300 & 460 & 480 & 400 & 440 & 300 & 440 & 130 \\
\hline $\begin{array}{l}\text { Total unit KJA *** } \\
\text { Total of unit cage culture fish }{ }^{* * *}\end{array}$ & 408 & 626 & 653 & 544 & 599 & 408 & 599 & 177 \\
\hline
\end{tabular}

Keterangan/ Note: * Ikan menggunakan $\mathrm{O}_{2}$ terlarut kira-kira $10 \%$ untuk respirasi/The fish respiration use about $10 \%$ of $\mathrm{O}_{2}$
dissolved

** Benih ikan berukuran 10 gram mengkonsumsi sebanyak 5 mg oksigen/jam (Hartoto, 1997)/ Fish seed of 10 grams consume $5 \mathrm{mg}$ oxygen/hour (Hartoto, 1997)

*** Ukuran keramba $7 \times 7 \times 2 \mathrm{~m}^{3} /$ Size per unit of cage $7 \times 7 \times 2 \mathrm{~m}^{3}$

Tabel 2. Rata-rata kelimpahan fitoplankton (sel/L) pada musim hujan di seluruh Waduk Jatiluhur*)

Tabel 2. Average of phytoplankton abundance(sel/L) on rainy season in Jatiluhur Reservoir*)

\begin{tabular}{|c|c|c|c|c|c|c|c|}
\hline \multirow{2}{*}{$\begin{array}{c}\text { Fitoplankton } \\
\text { Phytoplankton }\end{array}$} & \multicolumn{7}{|c|}{ Kedalaman (Depth) } \\
\hline & 0 & 1 & 2 & 3 & 4 & 5 & 10 \\
\hline \multicolumn{8}{|l|}{ Cyanophyta: } \\
\hline $\begin{array}{l}\text { Phormidium } \\
\text { Chlorophvta: }\end{array}$ & 952 & 816 & 1.428 & 884 & 1020 & 0 & 156 \\
\hline $\begin{array}{l}\text { Chiorophyta: } \\
\text { Chlorella }\end{array}$ & 204 & 884 & 1.972 & 1.088 & 476 & 1.088 & 1.224 \\
\hline $\begin{array}{l}\text { Staurastrum } \\
\text { Chrysophyta: }\end{array}$ & 1.836 & 2.786 & 5.780 & 1.360 & 3.128 & 2.380 & 4.624 \\
\hline Diatomae & 2.176 & 1.020 & 1.080 & 2.100 & 1.360 & 884 & 4.964 \\
\hline Navicula & 2.380 & 612 & 8.024 & 1.080 & 1.292 & 2.446 & 3.672 \\
\hline $\begin{array}{l}\text { Synedra } \\
\text { Pyrrophyta: }\end{array}$ & 1.292 & 2.992 & 4.828 & 3.332 & 1.360 & 1.972 & 3.808 \\
\hline Peridinium & 544 & 748 & 1.292 & 1.224 & 816 & 68 & 1.224 \\
\hline
\end{tabular}

Keterangan/Note:

*) Rata-rata kelimpahan fitoplankton dari 10 stasiun

*) Average of phytoplankton abundance from 10 stations 
Hasil pengukuran oksigen selama 24 jam menunjukkan bahwa pada musim kemarau umumnya kandungan oksigen terlarut $4 \mathrm{mg} / \mathrm{L}$, hanya mulai pukul 18.00 lapisan air di bawah $4 \mathrm{~m}$ kandungan oksigennya mulai berkurang dari $4 \mathrm{mg} / \mathrm{L}$, pada puncak kritis pukul 06.00 kandungan oksigen di bawah lapisan $2 \mathrm{~m}$ menurun (3,6 $\mathrm{mg} / \mathrm{L})$ dan meningkat lagi pada pukul 09.00 (Lampiran 1). Pada musim hujan kandungan oksigen terlarut umumnya rendah (di bawah $4 \mathrm{mg} / \mathrm{L}$ ) karena cuaca berawan atau hujan akan menghambat proses fotosintesis yang menghasilkan oksigen. Bila ditemukan dalam pengukuran oksigen tinggi (di atas $4 \mathrm{mg} / \mathrm{L}$ ) di daerah permukaan diduga karena goyangan/agitasi di daerah permukaan oleh angin atau hujan.

Perlu diketahui bahwa kandungan $\mathrm{O}_{2}$ rendah di perairan akan merangsang munculnya gas-gas racun seperti N-NH ${ }_{3}, \mathrm{H}_{2} \mathrm{~S}$, dan $\mathrm{CS}_{2}$ ataupun $\mathrm{CH}_{4}$ yang akan menyebabkan fatal bagi kehidupan ikan (Schmittou, 1991).

Dengan demikian keadaan ini perlu diwaspadai oleh petani ikan budi daya agar tidak terjadi musibah kematian ikan budi daya, walaupun menurut informasi sebelumnya jumlah KJA masih dibawah jumlah yang ditentukan.

Tabel 3. Rata-rata kelimpahan fitoplankton (sel/L) pada musim kemarau di seluruh Waduk Jatiluhur*)

Tabel 3. Average of phytoplankton abundance (sel/ ) on dry season in Jatiluhur Reservoir*)

\begin{tabular}{lccccccc}
\hline $\begin{array}{l}\text { Phytoplankton } \\
\text { Fitoplankton }\end{array}$ & $\mathbf{0}$ & $\mathbf{1}$ & $\mathbf{2}$ & $\mathbf{3}$ & $\mathbf{4}$ & $\mathbf{5}$ & $\mathbf{1 0}$ \\
\hline $\begin{array}{l}\text { Cyanophyta : } \\
\text { Anabaena }\end{array}$ & 1836 & 3944 & 2108 & 272 & 476 & 680 & 1224 \\
$\begin{array}{l}\text { Microcystis } \\
\text { Chlorophyta: }\end{array}$ & 0 & 0 & 68 & 0 & 0 & 204 & 136 \\
Chlorella & 4488 & 2312 & 1564 & 1836 & 1292 & 816 & 1292 \\
Cosmarium & 1632 & 1292 & 1292 & 952 & 952 & 748 & 1224 \\
Staurastrum & 1224 & 1360 & 1088 & 272 & 476 & 680 & 1224 \\
Chrysophyta: & & & & & & & \\
Diatomae & 544 & 544 & 1292 & 408 & 1156 & 1020 & 136 \\
Navicula & 68 & 136 & 408 & 68 & 136 & 340 & 68 \\
$\begin{array}{l}\text { Synedra } \\
\text { Pyrrophyta : }\end{array}$ & 3468 & 3128 & 3876 & 3468 & 2176 & 4080 & 3400 \\
$\begin{array}{l}\text { Peridinium } \\
\text { Detritus : }\end{array}$ & 2652 & 4284 & 3060 & 1768 & 1904 & 3060 & 2584 \\
\hline & 1496 & 1836 & 1632 & 1224 & 2920 & 544 & 1836 \\
\hline
\end{tabular}

Tabel 4. Klorofil-a di Waduk Jatiluhur ${ }^{* \star}$ )

Tabel 4. Chlorophyl-a in Jatiluhur Reservoir **)

\begin{tabular}{lccc}
\hline \multirow{2}{*}{ Bulan/Month } & \multicolumn{3}{c}{ Klorofil-a /Chlorophyl-a $\left(\mathrm{mg} / \mathrm{m}^{3}\right)$} \\
\cline { 2 - 4 } & Minimum & $\begin{array}{c}\text { Maksimum } \\
\text { Maximum }\end{array}$ & $\begin{array}{c}\text { Rata-rata } \\
\text { Average }\end{array}$ \\
\hline Mei, 1998 & 6.49 & 54.69 & $24.2 \pm 8.235$ \\
Juni, 1998 & 6.49 & 107.65 & $21.15 \pm 1.97$ \\
Juli, 1998 & 7.42 & 37.59 & $20.23 \pm 5.59$ \\
Agustus, 1998 & 6.5 & 25.06 & $15.22 \pm 4.12$ \\
September, 1988 & 7.42 & 19.49 & $12.05 \pm 2.60$ \\
Oktober, 1998 & 6.5 & 18.56 & $12.79 \pm 3.15$ \\
\hline
\end{tabular}

Keterangan/Note:

**) Nilai klorofil-a diperoleh dari rata-rata 7 stasiun pengamatan (KJAI,II,III,IV, Dam, Pagadungan, Warungjeruk) di seluruh Waduk Jatiluhur

*) Chlorophyll-a was observed from average of seven stations (KJA I,II,III,IV, Dam, Pagadungan, and Warungjeruk) 


\section{KESIMPULAN}

1. Daya dukung Waduk Jatiluhur untuk budi daya ikan dalam KJA tertinggi dicapai pada bulan Juli (musim kemarau) dan terendah pada bulan Desember (musim hujan). Pada bulan Juli total oksigen terlarut yang tersedia untuk ikan $240 \times 10^{10} \mathrm{mg}$ atau setara $480 \times 10^{3} \mathrm{~kg}$ ikan ( bobot ikan $10 \mathrm{~g} / \mathrm{ekor}$ ) dan setara 3.200-4.800 unit KJA (ukuran $98 \mathrm{~m}^{3} / \mathrm{unit}$ ). Pada bulan Desember (musim hujan) total oksigen terlarut yang tersedia untuk ikan $160 \times 10^{10} \mathrm{mg}$ atau setara dengan $130 \times 10^{3} \mathrm{~kg}$ ikan dan 867-1.300 unit KJA 17.687 unit (ukuran $98 \mathrm{~m}^{3} / \mathrm{unit}$ )

2. Daya dukung perairan Waduk Jatiluhur berfluktuasi sesuai dengan fluktuasi kandungan oksigen terlarut.

3. Untuk mengatasi kematian ikan pada budi daya ikan KJA disarankan agar pada bulan Desember (musim hujan) pembudidaya ikan mengurangi padat tebar ikan, menghindari pemeliharaan pada bulan tersebut atau mengganti jenis ikan yang toleran terhadap kandungan $\mathrm{O}_{2}$ yang rendah seperti ikan Pangasiodon hypopthalmus (patin siam).

\section{DAFTARPUSTAKA}

Beveridge, MCM. 1987. Cage Culture. Fishing News Books Ltd. England. $352 \mathrm{pp}$.

Gupta, J.S. 1981. Textbook of Algae. Published by Mohan Primlani, Oxford and IBH Publishing Co., New Delhi. $348 \mathrm{pp}$.

Hartoto, D.I. 1997. Notes on limnological condition of Lake Loa Kang as fishery reserve and its potential as food supply habitat for Mahakam Freshwater Dolphin. Seri Laporan PEP-LIPI No.7:63-85.

llyas, S dan A. Supardan. 1990. Keragaan perikanan dalam pembangunan jangka panjang tahap :I (19691993). Pros.Puslitbangkan/No. 18/1990. Badan Penelitian dan Pengembangan Pertanian. p.37-79.

Ismail, W dan S. E. Wardoyo. 1997. Peningkatan produksi ikan melalui penerapan teknologi budi daya keramba jaring apung (KJA) di perairan umum dan pantai laut. Prosiding Simposium Perikanan II, Ujung Pandang 2-3 Desember, 1997. Puslitbang Perikanan bekerja sama dengan JICA, UNHAS, Dinas Perikanan Dati I Sulawesi Selatan, ISPIKANI dan Himpunan Mahasiswa Perikanan Indonesia. p.174182.

Kartamiharja, E.S., 1995. Daya dukung perairan dan pengembangan budi daya ikan dalam keramba jaring apung yang ramah lingkungan. Prosiding Ekspose Budidaya Ikan dalam Keramba Jaring Apung yang Ramah Lingkungan. Pusat Penelitian dan Pengembangan Perikanan. p. $13-22$.

Kartamihardja, E.S. 1997. Pengembangan dan pengelolaan budidaya ikan dalam keramba jaring apung ramah lingkungan di perairan Waduk dan Danau Serbaguna. Prosiding Simposium Perikanan II, Ujung Pandang 2-3 Desember, 1997. Puslitbang Perikanan bekerja sama dengan JICA, UNHAS, Dinas Perikanan Dati I Sulawesi Selatan, ISPIKANI dan Himpunan Mahasiswa Perikanan Indonesia 1998. P:174-182.

Krismono, A. Sarnita dan A. Rukyani. 1996. 1600 Ton ikan mati di Waduk Jatiluhur. Warta Penelitian Perikanan Indonesia. Vol. I (1) : 5-7.

Nastiti, A.S. 1989. Suatu Pendugaan Status Air Perairan Waduk Juanda di Daerah Pasir Kole pada bulan Juni tahun 1988 ditinjau dari Aspek Sifat Fisika Kimia Air dan Fitoplankton. Fakultas Pascasarjana IPB Bogor. Tesis. $81 \mathrm{pp}$.

Nielsen, L.A. and D.L. Johnson. 1985. Fisheries Techniques. Americans. Fisheries Society, Bethesda, Maryland. $486 \mathrm{pp}$.

Prescott, G. W. 1970. The Freshwater Algae. WM. Brown Company Publishers. lowa.348pp.

Ryding, S.O. and W. Rast. 1989. The control of eutrophication of lakes and reservoirs. Man and the biosphere's series. Vol. I. UNESCO. Paris. 314 pp.

Schmittou, H. R. 1991. Cage Culture. A method of fish production in Indonesia. FRDP. CRIFI. Jakarta Indonesia. $114 \mathrm{pp}$. 
Lampiran 1. Kandungan $\mathrm{O}_{2}$ terlarut di Waduk Jatiluhur*)

Annex 1. Dissolved oxygen content in Jatiluhur Reservoir*)

\begin{tabular}{ccccccccc}
\hline \multirow{2}{*}{$\begin{array}{c}\text { Kedalaman } \\
\text { Depth }(\mathrm{m})\end{array}$} & \multicolumn{6}{c}{$\begin{array}{c}\text { Rata-rata oksigen terlarut pada 1998 } \\
\text { Average of dissolved oxygen in 1998 }\end{array}$} \\
\cline { 2 - 9 } & May & June & July & August & Sept. & Oct. & Nov. & Dec. \\
\hline $\begin{array}{c}0 \\
1\end{array}$ & $1.9-7.4$ & $4.0-9.0$ & $4.8-7.5$ & $4.7-6.7$ & $4.0-7.3$ & $2.6-5.7$ & $2.7-7.5$ & $1.9-6.2$ \\
5.8 & $1.7-6.8$ & $4.1-8.4$ & $4.6-7.1$ & $4.9-6.1$ & $3.3-7.1$ & $2.5-5.5$ & $2.7-7.3$ & $1.7-5.8$ \\
2 & $2.0-6.3$ & $4.1-8.2$ & $4.4-6.8$ & $4.3-6.2$ & $3.9-7.1$ & $2.5-5.5$ & $2.6-7.3$ & $2.0-5.2$ \\
5.2 & & & & & & & & \\
3 & $1.6-5.7$ & $4.0-7.9$ & $4.4-6.7$ & $4.1-6.1$ & $3.6-6.7$ & $2.5-5.2$ & $2.4-7.2$ & $1.6-5.2$ \\
5.2 & & & & & & & & \\
4 & $1.8-5.5$ & $3.7-7.6$ & $4.4-6.5$ & $4.0-6.1$ & $3.6-6.6$ & $2.5-5.1$ & $2.2-6.8$ & $1.8-4.8$ \\
4.8 & & & & & & & & \\
5 & $1.6-5.0$ & $3.7-7.3$ & $4.4-6.6$ & $3.7-5.9$ & $3.6-6.3$ & $2.4-4.6$ & $2.1-6.4$ & $1.6-4.8$ \\
4.8 & & & & & & & & \\
10 & $1.6-4.1$ & $3.0-6.8$ & $4.4-6.3$ & $4.1-5.6$ & $3.6-5.3$ & $2.3-4.4$ & $2.1-6.4$ & $1.6-4.4$ \\
4.4 & & & & & & & & \\
$21-54$ & $1.8-5.0$ & $2.3-6.0$ & $4.4-6.0$ & $3.6-5.4$ & $3.4-4.3$ & $2.1-4.2$ & $1.9-6.1$ & $1.6-4.0$ \\
4.0 & & & & & & & & \\
\hline
\end{tabular}

Keterangan/Note:

*) $\mathrm{O}_{2}$ diukur pada 10 stasiun (Dissolved oxygen measured at 10 stations)

Lampiran 2. Rata-rata kandungan $\mathrm{O}_{2}$ terlarut selama 24 jam di daerah KJA

Annex 2. Average dissolved oxygen content during 24 hours in fish net cage area

\begin{tabular}{|c|c|c|c|c|c|c|c|c|c|}
\hline \multirow{2}{*}{$\begin{array}{c}\text { Kedalaman } \\
\text { Depth }(m)\end{array}$} & \multicolumn{9}{|c|}{ Pukul (time) } \\
\hline & 9.00 & 12.00 & 15.00 & 18.00 & 21.00 & 24.00 & 3.00 & 6.00 & 9.00 \\
\hline \multicolumn{10}{|c|}{ September '98 (musim kemarau) } \\
\hline 0 & 5.2 & 5.4 & 6.6 & 4.6 & 4.5 & 4.2 & 4.1 & 4.0 & 5.6 \\
\hline 2 & 4.1 & 5.4 & 6.5 & 4.6 & 4.0 & 4.2 & 4.1 & 3.6 & 5.0 \\
\hline 4 & 3.8 & 4.2 & 5.0 & 4.4 & 4.0 & 4.0 & 4.0 & 3.4 & 3.8 \\
\hline 8 & 2.7 & 4.0 & 4.8 & 2.9 & 3.1 & 3.2 & 3.6 & 2.6 & 3.6 \\
\hline 40 & 2.5 & 4.8 & 4.2 & 2.4 & 3.0 & 3.1 & 2.0 & 2.5 & 3.0 \\
\hline \multicolumn{10}{|c|}{ Desember ' 98 (musim hujan) } \\
\hline 0 & 2.9 & 3.7 & 4.5 & 5.2 & 5.4 & 4.9 & 4.5 & 3.1 & 3.4 \\
\hline 2 & 2.8 & 3.4 & 3.6 & 4.6 & 4.8 & 4.5 & 4.5 & 2.9 & 3.2 \\
\hline 4 & 2.5 & 3.2 & 3.5 & 3.8 & 4.5 & 4.0 & 4.0 & 2.6 & 3.2 \\
\hline 8 & 2.3 & 3.2 & 2.9 & 3.4 & 3.7 & 3.3 & 3.2 & 2.2 & 2.8 \\
\hline 40 & 2.3 & 2.7 & 2.8 & 2.9 & 3.0 & 2.5 & 2.0 & 2.1 & 2.3 \\
\hline
\end{tabular}

Keterangan: pengukuran $\mathrm{O}_{2}$ terlarut dilakukan di daerah $\mathrm{KJA}$

Note : Dissolved oxygen measured in fish net cage area 